\title{
CORRESPONDENCE
}

\section{PhD: routine technical work of sequencing is no substitute}

You ask in an Editorial whether the Beijing Genomics Institute's strategy of tackling a huge research project by using a large team of new graduates could eventually displace a PhD degree as a model for the training and development of future scientists (Nature 464, 7; 2010). I don't believe so.

Although the institute's army of sequencers can produce impressive amounts of data, their individual capabilities are primarily technical and are limited to the field of genomics. They are unlikely to move on to conceptually more advanced projects, to publish their own results in world-class journals or to defend them at conferences.

Routine sequencing work cannot measure up to the standards of advanced education or creativity demanded by a formal PhD programme. The graduates at the Beijing Genomics Institute, like workers in any other industrial or academic setting, are mainly functioning as labourers to operate instruments and collect data.

China's higher-education system is expanding rapidly and the job market for new graduates is becoming increasingly tough. Central government is subsidizing academic institutions that hire them in an attempt to rectify the situation. The Beijing Genomics Institute's venture is therefore a response to political and social demand, rather than a genuine scheme to train future scientists. Most of the students will end up in non-academic positions where they are likely to be paid more.

A scientist has to be able to use the kind of logic and creativity that can really only be acquired through scientific education and training. To produce more creative researchers, China will need educational reforms that make doctorates seem more attractive and worthwhile to good graduates.

Yijun Chen Laboratory of Chemical Biology, China Pharmaceutical University, 24 Tongjia Street, Nanjing, Jiangsu 210009, China

e-mail:yjchen@cpu.edu.cn

\section{PhD: still necessary for independent research leaders}

Your Editorial poses the question of whether research scientists really need to have a PhD (Nature 464, 7; 2010). But the advanced training of future scientists is unlikely to be discarded in China or anywhere else - despite the success achieved by the Beijing Genomics Institute (or, for that matter, by Microsoft's Bill Gates and Apple's Steve Jobs).

The institute's research surpasses what is being done in many universities and research institutions in China, which in fields such as genomics, lack the funding and talent that leading, non-degree-granting organizations can provide.

The excitement of potential scientific achievement in such a rapidly developing field may be most palpable in places where the major action is happening. And these places attract aspiring researchers, with or without a doctorate.

China's rapidly growing economy and increasing prosperity have, paradoxically, enticed many professors away from their mentoring priorities. There is also fierce competition for research positions, created by the rapid expansion of $\mathrm{PhD}$ programmes in China over the past decade. These and other factors encourage prospective PhD students into non-academic careers.

China is no different from other countries, in that a doctorate is still necessary for independent researchers and group leaders. The Beijing Genomics Institute project is likely to be a laudable exception to the rule.

Yonghong Li Celera, 1401 Harbor

Bay Parkway, Alameda,

California 94502, USA

e-mail:yonghong.li@celera.com

\section{PhD: time and effort invested foster scientific maturity}

I question the adequacy of the training in research methods being acquired by the apprentice researchers at China's Beijing Genomics Institute (Nature 464, 7; 2010). My own experience suggests that their scientific maturity may not measure up to that gained through a $\mathrm{PhD}$ qualification.

I was forced to abandon my $\mathrm{PhD}$ after a year at the Indian Institute of Chemical Biology in Kolkata, because of the death of my supervisor. After two years lecturing in an engineering college in West Bengal, I joined the R\&D division of Maharashtra Hybrid Seeds, which was responsible for introducing India's first genetically modified crop, Bt cotton.

But my career prospects were evidently limited without a doctorate. Eventually, I enrolled at the age of 32 for a PhD at the Indian Institute of Technology Bombay. Besides the stimulation of working with a motivated group of research scholars in a wellfunded laboratory, there were lively weekly journal clubs and seminars.

In my view, time-constrained systematic laboratory training is essential for learning how to handle research projects independently. A PhD adds to the time needed to establish a career. But doctors, lawyers, chartered accountants and other professions all have to undergo comparable periods of gestation.

Biswa Prasun Chatterji Dulal Panda

Laboratory, Department of Biosciences and Bioengineering, Indian Institute of Technology Bombay, Mumbai 400076, India e-mail: biswaprasun@iitb.ac.in

\section{Food security requires genetic advances to increase farm yields}

J. R. Porter and B. Wollenweber claim in their Correspondence (Nature 463, 876; 2010) that improving the kinetics of the enzyme Rubisco and diminishing photorespiration are unlikely to increase crop productivity. But breeding as well as agronomy is necessary to enhance photosynthesis and meet the urgent global need for improved crop yields.

Enhancing photosynthesis by increasing Rubisco's carboxylation rate boosts biomass and yields, according to evidence from mechanisms such as $\mathrm{C}_{4}$ photosynthesis, which concentrates carbon dioxide, and studies of crop growth in a $\mathrm{CO}_{2}$-enriched atmosphere (E. A. Ainsworth and S. P. Long New Phytol. 165, 351-372; 2005) Improving Rubisco and engineering $C_{4}$ photosynthesis into $C_{3}$ crops such as rice are two approaches that we cannot afford to dismiss as gains from current agronomic strategies diminish.

Neither should we overlook the very real yield benefits of the 'Green Revolution'. Introducing dwarfing genes into cereals has enabled farmers to increase yields by using more nitrogen fertilizer without the risk of plants falling over. In wheat, dwarfing genes do not affect potential biomass production but increase allocation to grain (R. B. Austin et al. J. Agric. Sci. 112, 295-301; 1989).

Richard C. Leegood Robert Hill Institute, Department of Animal and Plant Sciences, University of Sheffield, Sheffield S10 2TN, UK e-mail:r.leegood@sheffield.ac.uk John R. Evans Research School of Biology, The Australian National University, Canberra, ACT 0200, Australia

Robert T. Furbank CSIRO Plant Industry and High Resolution Plant Phenomics Centre, GPO Box 1600 , Canberra, ACT 2601, Australia 